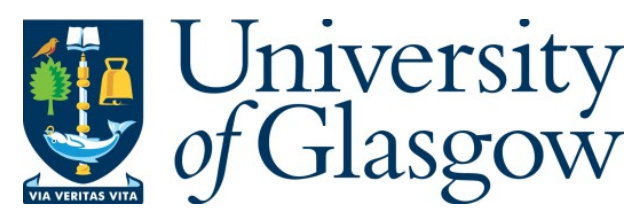

Leathwood, C. and Read, B. (2020) Short-term, short-changed? A temporal perspective on the implications of academic casualisation for teaching in higher education. Teaching in Higher Education. (Early Online Publication)

(doi: $10.1080 / 13562517.2020 .1742681)$

This is the Author Accepted Manuscript.

There may be differences between this version and the published version. You are advised to consult the publisher's version if you wish to cite from it.

https://eprints.gla.ac.uk/212303/

Deposited on: 16 March 2020

Enlighten - Research publications by members of the University of Glasgow http://eprints.gla.ac.uk 


\title{
Short-term, short-changed? A temporal perspective on the implications of academic casualisation for teaching in higher education
}

\section{Carole Leathwood and Barbara Read}

This is a post-peer-review, pre-copyedited version of an article accepted for publication in Teaching in Higher Education

\begin{abstract}
The increasing casualisation of academic labour over recent years has been noted across the global north. In the UK, this takes a number of forms, including fixed term, hourly paid and zero hours contracts. What tends to characterise them all, however, is a focus on the short-term. In this paper, we draw on a qualitative study with 20 UK-based academics on casualised contracts to consider the implications of the short-term nature of such employment for teaching and pedagogy. We come to this with a temporal perspective, in part in response to Felt's (2016) call for a chronopolitical analysis of the changing temporalities of academia. We discuss how short-term temporal logics marked by last-minute or 'just-in-time' modalities can be seen to impact negatively on teaching preparation and pedagogical relationships, raising questions about innovation and criticality, power and in/security, continuity and care.
\end{abstract}

\section{Key words}

Academics, casualisation, temporality, pedagogy, student-lecturer relationship

\section{Acknowledgements}

We would like to express our deepest thanks to all those who participated in this study and to the anonymous reviewers for their very helpful comments on an earlier draft. 


\section{Introduction}

Short-termism is now rife in UK higher education. It is reflected in both the short-term consumer rationality of student 'choice', individual modules, and fast turn-around assessments of 'customer satisfaction'; and in the pressure on academics to rapidly produce grant funding, a stream of 'excellent' publications and immediate impact (indeed to be able to foresee the impact of a research project before the project has begun). It is one aspect of a broader shorttermism across society in the context of globalised market competitiveness at a time of fast capitalism, where the casualisation of labour can be seen as part of a managerial drive for efficiency, rationalisation and flexibility. Drawing on data from 20 academic staff on casualised contracts in UK universities, we aim to contribute to and extend the developing debate on the casualisation of labour in the higher education sector in two ways. Firstly, we seek to foreground the under-researched issue of the effects of casualised contracts on teaching and the pedagogical relationship. And secondly, we explore ways in which our understanding of this issue can benefit from work conducted in the sociology of time (e.g.Adam 1995, 2001, 2008; Felt 2016; Lingard and Thompson 2017). In particular we argue for the need to apply a 'chrono-political' analysis (Felt 2016) to our understanding of the pedagogical impact of casualisation in higher education, in order to understand the relationship between the temporal logics of short-termism and unequal power relationships in the sector.

Academic casualisation has increased markedly across the global north over the last two decades (Gupta, Habjan, and Tutek 2016). Douglass (2015) notes that in American higher education in 1960, $75 \%$ of 'college instructors' were full-time tenured or tenure-track staff. By 2007, that figure had dropped to $31 \%$. In the UK, the Universities and College Union (UCU), 
concluded that as of 2014 'at least $54 \%$ of all academic staff and $49 \%$ of academics teaching in our universities are on an insecure contract' (UCU 2016, 4), predominantly at more junior levels. Women, Black and minority ethnic and disabled staff were over-represented amongst those on insecure contracts. Noonan (2015) argues that short-term academic contracts are no longer simply preparation for gaining a secure position but instead are increasingly substitutes for more secure posts. As Zheng (2018) notes, contingent academics are cheap, flexible and disposable, hence their appeal to universities in a hyper-competitive global market.

There has been a developing body of work on academic casualisation, much of which has focused on the impact of casualisation on academics themselves, including experiences of academic marginalisation and of financial and other insecurities (e.g.Loveday 2017; Ylijoki 2010; Acker and Haque 2017; Crawford and Germov 2015) and this is something we have begun to focus on in our own work (Authors, 2013; under review). Only a few studies (e.g. Lopes and Dewan 2014; Lama and Joullié 2015; Klopper and Power 2014; Street et al. 2012) explore the impact of academic casualisation on teaching, learning and the pedagogic relationship, and only one of these (Lopes and Dewan, 2014) has applied an explicit theoretical perspective (labour process theory) to their empirical findings.

We aim to contribute to and extend this debate by employing an alternative theoretical approach -temporality theory - in order to explore the complexities of casualised academics' perceptions of the impact that their contractual status has on their teaching and pedagogical relationships. We begin with an elaboration of the temporal theoretical approach that we are utilising, followed by an outline of the methodology of our research study, before discussing 
the key temporal themes that emerge in our data in relation to short-termism: last minute modality, time/space configurations, and security and continuity.

\section{Short-termism - a temporal perspective}

A temporal perspective can help to de-naturalise and problematise temporal structures, cultures and practices. Felt (2016) argues that we need a 'chronopolitical' analysis, a politics of time, to understand the changing temporal regimes of higher education. We suggest that shorttermism, as a particularly dominant temporality of contemporary higher education, is ripe for such an analysis.

In doing so, we draw on Barbara Adam's work in the sociology of time that recognises both the social construction of time and its complexities. She developed the concept of 'timescape' insisting that we cannot think about time without also acknowledging spatiality, materiality and embodiment, recognising that time is context specific. She defines timescape as 'a cluster of temporal features, each implicated in all the others, but not necessarily of equal importance in each instance' (Adam 2004, p143): time-frame, temporality, timing, tempo, duration, sequence and temporal modalities (past, present, future) (Adam 2008). Timescapes are therefore multidimensional, encompassing different and overlapping temporalities. They are lived and experienced differently - they are socially situated and shaped by power relations and inequalities (Burke et al. 2017).

Adam (2003) identifies what she refers to as 'five Cs' of industrial modernity, all of which will be familiar to academics in today's academy: 'the creation of time to human design' or 'clock 
time', the commodification of time (or 'time is money'), the compression of time (speeded up time), the control of time (to ensure efficiency and productivity) and the colonization of time (the way particular temporal rationalities dominate and colonise other time). She notes that 'When time is money, then faster means better' (ibid., 67), hence the intensification of work. In this framing, time is decontextualized, seen as an abstract standardised unit, a neutral exchange value, and any time that does not equal money is wasted time (Adam 2001). Marx argued that in this rationalisation of work:

Time is everything, man [sic] is nothing; he is at the most the incarnation of time.

Quality no longer matters. Quantity alone decides everything: hour for hour, day for day (Marx, 1847 cited by Lukacs 1971, 89-90)

Time can therefore be seen as a technology of governance. Over a century and a half after Marx was writing, we are in very different times. Neoliberalism, understood broadly as the uneven and 'politically guided intensification of market rule and commodification' (Brenner, Peck, and Theodore 2010, p. 184) spread across the globe from the 1980s, albeit in different iterations (ibid.). The rapid increase in the casualisation of labour over the last two decades is part of this development. As Ball (2012, p.18) notes, however, neoliberalism is not only an economic and political project through which market and business practices are spread throughout higher education (and the rest of the public sector), but 'it gets into our minds and our souls, into the ways in which we think about what we do, and into our social relations with others'. The insecurities generated by casualisation, the proliferation of performance indicators and processes of audit can all be seen as part of this neoliberal temporal regime of governance. Felt (2017, p. 54) argues that 'major temporal reorderings within academia stand in coproductive relationship with the growing number of indicator systems'. The resulting expectations of academic productivity become internalised producing a new form of 'tacit governance' (Felt and Fochler 2010). The performance of individuals (as well as departments 
or universities) is then used to measure productivity and/or 'quality', with Ball (2003, p.216) stating that:

Performativity is a technology, a culture and a mode of regulation that employs judgements, comparisons and displays as means of incentive, control, attrition and change based on rewards and sanctions (both material and symbolic).

Quantification and measurement now dominate academic life and have come to signify academic value. Workload models and 'transparency' audits aim to prescribe and quantify the amount of time academics spend on teaching, marking, research, etc., but such prescriptions often bear little relation to actual hours worked, reflecting only the proportion of time allocated to each activity (Burrows 2012). The highly gendered 'housework' and care work of the university (Guarino and Borden 2017; Lynch 2010) is not only hidden from sight and recognition, but is further devalued through such audit technologies, with women on precarious academic contracts doing most of this 'domestic' work (O'Keefe and Courtois 2019). Any consideration of the relational, the embodied and the affective, including the psychosocial costs for academics (Gill 2010), are excluded from such technically rational conceptualisations of time. As Bennett and Burke (2017, p. 4) argue 'we experience time according to context, subjectivity, and positionality', an experience that is shaped by economic, social and cultural inequalities (Burke et al. 2017). Adam (1995) notes how dominant conceptions of linear western time are used in a 'chronology of difference' though which Others are measured and deemed lacking though colonial logic - left-behind, undeveloped, slow, lazy, etc. (Shahjahan 2015). A sense of not having 'enough' time impacts upon both academics and students (Burke et al. 2017; Brew 2015), yet as Walker (2009) noted, time has become a matter of morality, with those not deemed to be 'keeping up' or making the best use of their time seen as individually responsible. The affective dimensions of this in terms of failure, guilt and shame 
are all too evident in the literature (see e.g. Shahjahan 2015; Burke et al. 2017; Gill 2010; Bunn, Bennett, and Burke 2018).

Social acceleration (Rosa 2015), or the increased intensity and tempo of academic life (Clegg 2003), is a key element of this temporal transformation of academia. Peters (2015, p. 44), noting that speed 'defines contemporary capitalism as - "fast" capitalism', argues that universities are "'engines of innovation" for "fast capitalism"' (ibid. p. 39), operating as part of the "global financial culture'. Digitised communication technologies facilitate what Hassan (2017) refers to as 'network time', a form of timescape that has open-ended acceleration potential. Sabelis (2008, p 129) describes this speeded up working life as follows:

The temporal regimes of output-driven management are ruthlessly applied to organizations, ruling out the biological, the social, the intercultural, the long-term evolutional, the implicit conditions that make us want to work. Short-term views rule: monthly, weekly, daily output schemes have replaced what we might call a natural rhythm determined by work motivation, pleasure in getting things done, and the expectation of rest after a hard day's work.

Of course, academic work has always encompassed the different and multiple temporalities of teaching, research and administrative tasks, but the impact of 'output-driven' demands and the modularisation of the curriculum reflect the increased short-termism that Sabelis above identified, leading to the intensification of what Felt (2016) has described as 'profound temporal inconsistencies' that have led to a 'hyperfragmentation of time' amongst academic researchers. 
The fragmentation of research into time-limited discreet projects, reflecting the 'grants culture' commercialisation and commodification of research identified by Baez and Boyles (2009), has been conceptualised by Ylijoki (2015) as 'project time'. Like 'clock time' it is decontextualized, linear, standardised, measurable and predictable, with a fixed start and enddate. It is cost-efficient, valorising speed, and its short-term timeframe leads to the employment of short-term workers. Project time, Ylijoki (ibid. p 100) argues, 'glorifies new virtues in academic research, such as economic rationality, instrumental orientation, efficiency, accountability, short-termism and speed'.

Although Ylijoki focuses mostly on research, she acknowledges the conflicts between project time and teaching, noting that both have their own temporalities. Teaching can also be seen to have short and fixed timeframes of classes, semesters and assessment deadlines, in contrast to the open-ended time of traditional scholarly research. But not all teaching and learning is so short-term, with doctoral study taking place over at least three years, and often much longer, which is a significantly longer timespan than most short-term academic contracts. Although, in a reflection of the 'project time' rationalities identified by Ylijoki, increasing pressure is being placed on research students and supervisors to ensure completion of research degrees in the shortest possible time.

The different temporalities of open-ended 'blue skies' academic research and the short-term projects that Ylijoki discusses can also be seen reflected in different pedagogical approaches. There has been a long tradition of critical pedagogies in the academy, including Freirean influenced and feminist pedagogies, that have highlighted issues of criticality, power, relationality, inclusivity and care in the teacher-student relationship. Such pedagogies tend to 
assume a timeframe and duration conducive to the development of relationships, a temporal modality that focuses more on process than on future outputs, a sequencing that facilitates the development of critical engagement, and a tempo that offers time for thoughtful reflection.

In contrast, in the context of neoliberalism and the focus on audit, competition, performativity and 'student (or 'customer') satisfaction', the framing of pedagogical relationships in terms of a service-provider/student consumer model has gained prominence along with output-focused utilitarian pedagogies. These tend to emphasise time efficiency, shorter duration and a faster tempo. Short-term contracts for academics fit perfectly with this temporal framing, whilst critical pedagogies are positioned as 'out of place' or, indeed, as 'out of time' with potentially serious consequences for knowledge and pedagogy. This provides another reminder of time as a technology of governance, of 'the imposition of a temporality by powerful others through the externality of control' (Gibbs 2015, p 53). Whilst this affects all academics, the temporal logics of short-termism have particular resonance for those on casualised academic contracts, as this study illustrates.

In this paper, we draw on this work in the sociology of time to explore the implications of such short-termism for teaching and pedagogical relationships in the contemporary UK academy. We recognise that the dominant temporal terrain of neoliberalism and fast capitalism, and the temporal structures and dynamics of universities, are not experienced by everyone equally, hence the importance of a chronopolitical analysis to illuminate the entanglements of time with issues of power and control (Felt 2016). We begin with an exploration of short-termism and what we identify as a 'last-minute modality', for example, where casualised academics receive 'last-minute' notification of their forthcoming teaching. This is followed by a discussion of 
'time/space configurations', including issues relating to the time and material space such staff have in which to conduct tutorials. The final section, on issues of 'security and continuity', illustrates how lack of knowledge or certainty about future academic contracts impacts on pedagogical relationships with students. In each of these sections, a chronopolitical analysis enables us to highlight the power relations in play, in particular related to the marginalisation and relative lack of power and control of casualised academic staff.

\section{The Study}

The research on which this article is based was designed to explore the perceptions and experiences of casualised academic staff as to the effects of casualisation on the teaching and learning of undergraduate students. The study involved qualitative email interviews, conducted between November 2017 and August 2018, with 20 UK-based academics on fixed-term, hourly-paid or similar forms of insecure academic contract, who taught to some extent as part of their academic duties. Potential participants were invited to take part in the study through emails circulated to selected UK academic networks including disciplinary-based associations, learned societies and the Universities and Colleges Union. The final sample (based on participants' self-identification - see Table 1) included 17 women and 3 men. Most were under 40 , although two were aged 41-50, one 51-60 and one 60+. The sample was predominantly white (19 participants) and middle class (15 participants). One identified as Black African Caribbean, another as white Jewish and two as white non-UK (German and continental European). There was a mix of primary disciplines amongst the participants, with 10 broadly within the social sciences, two in the sciences and eight in arts/humanities. Just under half of 
the sample had less than five years teaching experience, nine had 6-10 years' and two had over ten years. Pseudonyms are used throughout.

Insert Table 1 here

Email interviews enabled busy academics to respond to our questions at a time that suited them, and to reflect on their answers before sending them to us. This approach therefore offers a different temporal dimension from face-to-face interviews (James 2016), one that has been used successfully in other social research and in our own previous study with academics (Authors 2012, 2013). It is possible, of course, that the narrative style of response that email interviews could be seen to encourage may have contributed to the gender-imbalance of our sample: not only did we attract more women participants than men, but their responses were notably longer on the whole. The opportunity, however, to engage in an email dialogue over time enabled us to follow-up on responses and probe further as appropriate. Our main questions were sent in two stages, with all but three participants completing both stages. In addition, we sent follow-up emails to clarify particular points in their responses as appropriate and to explore key issues in more depth as these emerged in our analysis. We adopted a thematic analytical approach (Braun and Clarke 2006) along with temporality theory, with both researchers involved in coding and analysis, and checking our interpretations with each other and against the data through an iterative process.

\section{The implications of academic casualisation for teaching in $\mathrm{HE}$}

In response to questions about the perceived impact of participants' contractual status on teaching and pedagogical relationships, the marginalisation of casualised academics and the 
insecure short-term nature of their employment underpinned many of the issues raised. Below we discuss the key temporal themes that emerged in relation to short-termism under three headings: last minute modality; time/space configurations; and security and continuity.

\section{Short-termism and last minute modality}

The difficulties resulting from the last-minute notification of teaching were raised repeatedly in our study. For example, Olivia explained:

I was also not told I was convening an additional module until I arrived back this week - there was no forewarning or handover or time to prepare and many colleagues in my position have experienced similar issues.

Yvonne also explained that she usually didn't know until the week before teaching begins what modules would be offered to her, explaining that it was because 'I am often not considered for work until after full time members of staff allocations are completed'. Universities' desire for 'efficiency gains' result in pressure on managers to ensure that all established academics are given their full teaching timetable before spending on hourly paid lecturers can be justified. Full-time established academics are therefore required to fit more teaching into their week, just one aspect of what Gill (2010, p. 234) has referred to as 'a punishing intensification of work [that] has become an endemic feature of academic life'. However, this last minute notification of teaching illustrates the ways in which timescapes encompass multiple temporalities which can be experienced very differently - here the timing and sequencing of activities differentially impact on casualised academics (and, potentially, their students) who tend to have the least autonomy and to be the last to be notified. As such they bear the brunt of what resembles a 'just-in-time' economy, that may work well for fresh food imports, but not for academics committed to providing well prepared teaching activities. 
For Louis, who had worked for ten years in the same Russell Group university, such last-minute temporal modalities had both affective and pedagogical consequences:

There have been difficult periods, particularly at the junction between my three contracts. My contracts typically run out at the end of August, the new contracts would then start in September. But in all instances when I was in the process of getting a new contract, all the key stages happened at the very last minute, with one particularly stressful period where I had to have an interview on the last day of my then current contract, and receiving a formal job offer from the University a few days after.

Louis felt that the quality of his teaching suffered in consequence.

For some participants, lack of autonomy in what they were required to teach compounded the difficulties of last-minute notification. Julia, for example, explained that in a post-92 university where she worked, she was only given the lesson plan the night before she was expected to deliver it:

I was expected to teach in line with a very rigid, detailed plan made by the module co-ordinator which was sent between $9 \mathrm{pm}$ and 12 am the day before the seminar each week. Sometimes, this dropped into my inbox as late as $2 \mathrm{am}$ on the day of the seminar. [...] I often tried to stay awake until I received the plan, and had I not received it by around midnight, wake up incredibly early in the morning to [prepare] before heading out to teach the 9am seminar.

Julia went on to explain that she was also unable to tell students what they would be covering in later sessions as she had not been given that information, something that was both frustrating for the students and impacted on her confidence in her teaching. Given the intensification of 
academic work, it is likely that the module tutor is also juggling multiple demands and resorting to last-minute teaching preparation, but the lack of autonomy and power of the casualised academic means that she is left waiting for the information she requires, leaving almost no time at all to prepare or reflect, let alone be creative or innovative in her teaching. Any preparation she does have time to do inevitably demands an increased tempo within a compressed and inflexible timeframe, contributing to her stress levels and potentially impacting on the quality of what she is able to deliver for the students. For the academics in this context, speed and instrumentalism become valorised to survive in the present moment - a 'forced presentism' (Read and Leathwood 2018), in contrast to the 'present future' temporal modality of dominant pedagogies and discourses of employability (Clegg 2010) which inevitably invoke students to orient themselves towards at least the short-term future of assessment and grades. These different and conflicting temporal modalities can result in instances of tension with affective consequences for both academics and students.

The desire to provide high quality teaching and learning experiences was evident throughout the data, but this was further compromised when last-minute notification of teaching was compounded by 'rarely having the opportunity to teach the same thing twice' (Jack) and teaching outside one's area of expertise which, meant, as Zoe argued, that 'students lose out'. Changing out-dated curriculum content was also difficult in these circumstances. Jane, for example, reported that last-minute notification made it hard for her to change a pre-existing module that was 'very white and male', whilst Jennifer explained:

I also experienced teaching on a model about sociological theory when it was the usual Durkheim and his white-man gang and I wasn't in a position to change that as I arrived only a couple of weeks before term started. I decolonise and genderised where I could but I didn't know that when I left it wouldn't go back to before so 
you almost think why bother. In that sense, there is no space for you or the curriculum to develop or to have real changes.

Brew (2015), in her research with academics, also discovered that lack of time to develop alternatives hindered teaching innovation, and as Buddeberg and Hornberg (2017) note, social acceleration means that knowledge is deemed 'out of date' and loses its validity far more quickly than in the past, making it even more important that academics have the opportunity to adapt the curriculum. As Bianca said:

I'd love the opportunities to think of highly engaging and innovative approaches or sources to have in class every week, but sometimes (not always) there just isn't time to do this, and I don't feel students get the best of my teaching.

Anton also declared that 'the quality of teaching suffers from this employment situation', though he tempered this by noting that the desire to get a new contract and fear of negative student feedback meant that some casualised academics feel they have no choice but to put in extra hours, again highlighting the role of the commodification of time in relations of power and inequality (Adam 2001). Similarly, Zoe explained:

The vulnerability of being on a fixed-term, and until recently part-time contract made me feel like I had to give much more to my students because otherwise they might complain about me and put my employment at risk.

The fear that Anton, Zoe and other participants report can be seen as an example of the 'politically induced' insecurities (Authors 2018; Lorey 2015) about present and future employment that are one aspect of neoliberal forms of governance that work to invoke compliance. 
The temporal dynamics of intensification and short-termism valorise output-focused pedagogies, shorter modules rather than year-long courses, and delivering knowledge (or information) in 'bite-sized' pieces. They compromise the 'thought-time' (Noonan 2015) necessary for academic research, teaching and learning, and as Gibbs (2015, p. 54) notes, the commodification of time 'works against reflection on critical learning and any vision for the development of the dignity of human rights, democracy and being'. Whilst these are issues for all academics in the contemporary academy, the temporal logics of short-termism has particular resonance for the knowledge that is generated and for student learning.

\section{Short-termism and time/space configurations}

Despite their best efforts to support students, the contractual status and material conditions of casualised academic labour were seen to impact negatively on pedagogical relationships by many of the participants, with Poppy declaring 'Supervision in public spaces; limited time in the week to support. I certainly can't see any ways in which it improves experiences.'

A recurring theme was the lack of time and space to get to know students, with most of the participants indicating that they did not have an office space in which to meet students outside class time, nor did they receive any payment for this. Office space is both a spatial signifier of being recognizable as an academic subject and also a temporal marker of relative permanence - of having a future at the institution. Casualised academics on short-term contracts are continually reminded of their lack of permanence and security, and of their marginalisation in the academy, through the lack of office space (and their name on the door) in which to engage in the everyday activities and rhythms of academic life - of reading, teaching preparation, student support/tutoring, marking and reflection. Bianca explained: 
At the second HEI, I was never assigned a space nor time for my office hour, and had to hold it every week in Costa Coffee on campus - which, in the run up to Christmas, was busy, noisy and the opposite of private. I repeatedly asked but was ignored. It was difficult for students and almost impossible for me to retain a professional atmosphere and environment under these conditions.

Motta and Bennett (2018) note that pedagogies of care require time and pedagogical spaces to enable attentiveness to the affective and the embodied aspects of learning and to foster a sense of safety and belonging, which is especially important for students for whom educational spaces may evoke anxiety or fear. However, both time and space are seriously compromised for many marginalised academics on short-term contracts. Julia, who also spoke about seeing students in the corridor or campus cafes and raised concerns about issues of confidentiality, went on to explain that module tutors were expected to run an office hour, although she was advised that it wasn't expected of her as she was not paid for that (and had no office). But she explained:

However, I felt pressure to, as every other module tutor (that were permanent fulltime members of staff) offered this to students; I did not want to be seen by students as not providing them with opportunities to discuss their concerns. In the students' eyes, I was no different from their other tutors. I was still responsible for teaching them a module, marking their work and supporting them academically. The only difference was my contract.

This illustrates the ways in which fast capitalism, neoliberal technologies and the temporal rationalities of the commodification of time responsibilise individual gendered subjects, necessitating unrecognised emotional labour for Julia when considering whether or not to 
provide an office hour and guilt should she decided not to. Julia insisted that she put in additional unpaid hours because of her commitment to students: 'I did this not because I wanted to 'impress' management or anyone else. I did this because I cared about the students and their success.' Julia, we suggest, is 'time giving' (Adam 2001), going beyond the commodified 'time-as-money' framing though her concern for her students. As Adam (ibid. p 7) notes 'in interaction we generate and make time' and 'social relations are permeated by time giving'. Although Adam is largely conceptualising this in terms of familial and social relations outside the employment sphere, 'time giving' also appears to be taking place here, where Julia and other participants discuss working significantly in excess of their paid hours to support their students. Serena suggested that such commitment had a gender element, arguing ' $m y$ impression is there's a general gender gap in time and effort and care with students', a perception that has also been reported in the research literature (e.g. Guarino and Borden 2017) and which has particular implications for women academics, with Cordozo (2016, p. 4) noting that 'there is an inverse relationship between who cares and who advances'. Cordozo (ibid. p.5) argues that the casualisation of academic labour:

..reconstructs teaching as "poorly paid housework in the marketplace," where some tend to the (college) kids and maintain the (departmental or campus) home, while others engage in more "productive" work that circulates on the market. Viewing teaching and service as care work thus clarifies the invidious gendered and racialized logic by which the complex work of "professing" has been unbundled into a two-tiered system of academic labor that also devalues caring activities within the tenure system.

As Adam (2001, p. 21) writes, 'not all times are equal. Not all working time is renumerated. Yet all work relations touched by clock time are tied up with hegemony and power'. 
Others attempted to fit individual student support into paid contact time, highlighting how time becomes compressed and reflecting how 'time is money' is an issue both for the managerial university and for casualised academics. Both Kathleen and Sally described finishing classes early to leave a bit of time to see students individually. Sally explained that she did not have an office, nor payment to offer an 'office hour' and added:

Students don't necessarily know why I can’t offer them office hours or a space and time to feedback on their work. This often ends up taking place quickly at the end of the seminar.[...] The seminars are 2 hours long and I often finish 15 minutes early so as to leave time for students to approach me with questions. This occasionally results in a short queue of people waiting and so is not a private space. It also may put students off as it feels like the end of the seminar and that everyone is keen to leave.

The temporal acceleration and compression of academic life impacts upon both academics and students, who are managing what are often complex and contradictory timescapes of paid employment, study, family, caring and living. The absence of paid time and space for academics on short-term contracts can be seen to add to the emotional labour and stress of dealing with this complex temporal terrain. These academics are marginalised, and their students compromised, not only by being denied material resources such as an office, but also because they are excluded from the same temporal regimes as more established academic staff.

\section{Short-termism, security and continuity}

Karpouza and Emvalotis (2019) note that pedagogical relationships in higher education are complex dynamic processes that develop over time, but this presents significant difficulties for 
those academics (and their students) teaching ad hoc sessions on very short-term contracts, for whom their contractual status mitigates against longer, sustained relationship building. Jack suggested that short-term contracts may mean 'that both sides invest less in that relationship', although he went on to indicate that he didn't think this was the case due to pressure to do the job well in the hope of future employment. But others felt that lack of continuity, and the uncertainty involved in not knowing if contracts would be renewed, impacted negatively on pedagogical relationships with students. Jennifer said:

I know from the teaching evaluations I've seen that students like continuity and developing relationships with colleagues and that this can't happen in a casualised workforce.

Sara also commented that 'there's no continuity' and said it meant she couldn't 'follow student progress or provide certain kinds of support', whilst Olivia stressed the lack of continuity year to year and the importance for students to have 'good working relationships with their tutors'. Tracey added that lack of continuity was a problem when students need advice or references. For critical and feminist pedagogical work in particular, the opportunity to build relationships and trust over time is important, especially for what Lennon et al (2018) call 'uncomfortable teacherly moments'. Similarly Henderson (2019, p. 116), notes that in feminist pedagogies the tendency is 'to imagine a teacher-student interaction that develops over time (where time is imagined in weeks, months and even years, rather than minutes or hours)' and she goes on to discuss the consequent difficulties of introducing feminist pedagogy in a one-off guest lecture.

As discussed above, teaching one-off sessions on someone else's module can lead to difficulties when students ask about the content of future sessions. But uncertainties about the 
future or a forced 'presentification' (Leccardi 2005) also made it impossible for some participants to offer reassurance about their own continued availability to students:

Students don't have personal tutors all the way through their degrees because their tutors leave when on temporary contracts. This has affected some of my personal tutees' ability to seek help for mental health problems and to talk about difficult family experiences. One of my new students asked me in October if I was going to be there for the whole year because she'd had three tutors so far, and I couldn't give her a definite answer. (Zoe)

I had one class that sought reassurance from me, repeatedly, that I would not leave mid-way through the semester. This was due to them having experienced four different tutors in one module in a short space of time in the previous year, which they felt had negatively impacted their progress. (Julia)

As Clegg (2010, p. 345) notes, 'the dominant modality of pedagogical discourses in higher education involves an orientation towards the future; temporality is coded as future time for the person, their achievements, and their employability'. For the students, a future-focused temporal trajectory towards hopefully successful achievement is lived, and felt, in the present, along with the anxieties, fears and uncertainties that accompany the temporal rhythms of assessments deadlines, semesters and academic years. The conflicting temporalities of precarious short-term academic contracts and students on year-long (or indeed, three-year long) courses can be seen to have affective consequences for both academics and students, and these are likely to be intensified for those from under-represented, less powerful and marginalised groups. Julia went on to report that some personal tutees had wanted her to support them through their final year dissertations, something she was unable to commit to as she may not be teaching then, and Jack reported that some Masters students he had taught wanted him to supervise their $\mathrm{PhDs}$ which again, he was not able to agree to. 
Kathleen summed up what she saw as the problem of short-termism:

We're in a situation where the long-term growth of students can't be a part of the teachers' experience of their work, and the students lose out on having a lasting connection to their instructors if there is no certainty about continuity. I feel like I'm in a classroom to get through some curriculum, but attempts to engage students becomes more about reversing poor retention metrics than supporting fellow humans on a longer intellectual and personal journey through their education.

Kathleen's words reflect the conflict between the temporalities of more traditional (critical/feminist) pedagogies with a focus on the longer-term growth of students, and outputfocused ones, where what is important is meeting targets, 'ticking the boxes' and ensuring that performance indicators such as retention rates are met. Katherine asserts that both academics and students lose out when the focus is on the latter.

\section{Concluding Comments}

The specific contribution of this article has been to bring a chronopolitical analysis to the ways in which a 'short-term' temporal rationality impacts specifically on casualised academics and on their teaching and pedagogical relationships with students. Such an analysis helps us to understand the relationship between the temporal logics of short-termism and unequal power relations in the higher education sector. We have shown how these temporal logics mitigate against equality (see Adam 2001): it is those academics who tend to be the most marginalised and least powerful in their institution who bear the brunt of these short-term rationalities. The examination of last-minute modality illustrates how the intensification and acceleration of work 
in the academy has particular resonance for casualised academics whose relative lack of power and status mean they are at the bottom of the hierarchy in terms of teaching allocations and hence at the sharp end of a last-minute temporal logic - as are their students. This impacts on the time these academics are able to devote to teaching preparation and to innovative and creative curricula and pedagogical interventions. The time/space configurations within which casualised academics are located, evident particularly in the lack of office space or allocated time for tutorials, can be seen to have serious implications for student support and advice, despite academics' attempts to mitigate these material inequalities through 'time giving' (Adam 2001). The relative lack of security and continuity endemic in casualised academic labour further compromises the development of meaningful pedagogical relationships, with both academics and their students mired in uncertainty and insecurity. Such short-term rationalities can be seen to restrict opportunities to manage multiple and often competing temporal demands. Teaching and curriculum innovation as well as pedagogies of care are compromised in these time/space configurations, striking at the heart of much that academics and students value in higher education. Felt (2016) calls for 'practices and policies of temporal care' in the academy. Such a move is essential if we are to move beyond Lynch's (2010) 'careless' academy, but it needs not only a recognition of the gendered politics of time, but also a move away from academic casualisation to ensure that both academics and their students are able to devote time to high quality teaching and learning.

\section{References}

Acker, Sandra, and Eve Haque. 2017. "Left Out in the Academic Field: Doctoral Graduates Deal With a Decade of Disappearing Jobs." Canadian Journal of Higher Education 47 (3):101-19. doi: $10.1080 / 13676260701800753$.

Adam, Barbara. 1995. Timewatch: The Social Analysis of Time. Cambridge, UK: Polity Press.

--- 2001. When Time is Money: Contested rationalities of time and challenges to the theory and practice of work, Working Paper Series Paper 16. Cardiff: Cardiff University. 
-- - 2003. "Reflexive Modernization Temporalized." Theory, Culture \& Society 20 (2):59-78. doi: 10.1177/0263276403020002004.

-- - 2004. Time. Cambridge: Polity Press.

- - 2008. "Of Timescapes, Futurescapes and Timeprints." In. www.cardiff.ac.uk/socsi/futures/conf ba lueneberg170608.pdf: Talk at Lüneburg University, 17 June 2008.

Baez, Benjamin, and Deron Boyles. 2009. The Politics of Inquiry: Education Research and 'the Culture of Science'. Albany: State University of New York Press.

Ball, Stephen J. 2003. "The Teacher's Soul and the Terrors of Performativity." Journal of Education Policy 18 (2):215-28.

Ball, Steven J. 2012. "Performativity, commodification and commitment: An I-Spy Guide to the Neoliberal University." British Journal of Educational Studies 60 (1):17-28.

Bennett, Anna, and Penny Jane Burke. 2017. "Re/conceptualising time and temporality: an exploration of time in higher education." Discourse: Studies in the Cultural Politics of Education:1-13. doi: 10.1080/01596306.2017.1312285.

Braun, Virginia, and Victoria Clarke. 2006. "Using thematic analysis in psychology." Qualitative Research in Psychology 3 (2):77-101.

Brenner, Neil, Jamie Peck, and Nik Theodore. 2010. "Variegated Neoliberalization: geographies, modalities, pathways." Global Networks 10 (2):182-222. doi: 10.1111/j.14710374.2009.00277.x.

Brew, Angela. 2015. "Academic Time and the Time of Academics." In Universities in the Flux of Time: An exploration of time and temporality in university life, edited by Paul Gibbs, Oili-Helena Ylijoki, Carolina Guzman-Valenzuela and Ronald Barnett, 182-95. London: Routledge.

Buddeberg, Magdalena, and Sabine Hornberg. 2017. "Schooling in times of acceleration." British Journal of Sociology of Education 38 (1):49-59. doi: 10.1080/01425692.2016.1256760.

Bunn, Matthew, Anna Bennett, and Penny Jane Burke. 2018. "In the anytime: Flexible time structures, student experience and temporal equity in higher education." Time and Society 0 (0):1-20.

Burke, Penny Jane, Anna Bennett, Matthew Bunn, Jacqueline Stevenson, and Sue Clegg. 2017. It's About Time: Working towards more equitable understandings of the impact of time for students in higher education. http://shura.shu.ac.uk/15364/: Sheffield Hallam University.

Burrows, Roger. 2012. "Living with the H-Index? Metric Assemblages in the Contemporary Academy." The Sociological Review 60 (2):355-72. doi: 10.1111/j.1467-954X.2012.02077.x.

Clegg, Sue. 2003. "Learning and teaching policies in higher education: mediations and contradictions of practice." British Educational Research Journal 29 (6):803-19. doi: 10.1080/0141192032000137312.

- - . 2010. "Time future - the dominant discourse of higher education." Time and Society 19 (3):345-64.

Cordozo, Karen M. 2016. "Academic Labour: Who Cares?" Critical Sociology:1-24.

Crawford, Tina, and John Germov. 2015. "Using workforce strategy to address academic casualisation: a University of Newcastle case study." Journal of Higher Education Policy and Management 37 (5):534-44. doi: 10.1080/1360080X.2015.1079394.

Douglass, John Aubrey. 2015. "Organizational Devolution: The old, new and future American research universities in the age of privatization." In Universities in the Flux of Time: An exploration of 
time and temporality in university life, edited by Paul Gibbs, Oili-Helena Ylijoki, Carolina Guzman-Valenzuela and Ronald Barnett, 57-76. London: Routledge.

Felt, Ulrike. 2016. "Of Timescapes and Knowledge Scapes: Re-timing Research and Higher Education." In New Languages and Landscapes of Higher Education, edited by Peter Scott, Jim Gallacher and Gareth Parry, 129-48. Oxford: Oxford University Press.

- - - 2017. "Under the Shadow of Time: Where Indicators amd Academic Values Meet." Engaging Science, Technology and Society 3:53-63.

Felt, Ulrike, and Maximilian Fochler. 2010. "Re-Ordering Epistemic Living Spaces: On the tacit governance effects of the public communication of science." In The Sciences' Media Connection - Public Communication and its Repercussions, edited by Simone Rödder, Martina Franzen and Peter Weingart, 133-54. Netherlands: Springer.

Gibbs, Paul. 2015. "If time doesn't exist, why are we learning about the past?" In Universities in the Flux of Time: An exploration of time and temporality in university life, edited by Paul Gibbs, Oili-Helena Ylijoki, Carolina Guzman-Valenzuela and Ronald Barnett, 46-56. London: Routledge.

Gill, Rosalind. 2010. "Breaking the Silence: The hidden injuries of the neoliberal university." In Secrecy amd Silence in the Research Process, edited by Róisín Ryan-Flood and Rosalind Gill, 228-44. London: Routledge.

Guarino, Cassandra M, and Victor M H Borden. 2017. "Faculty Service Loads and Gender: Are Women Taking Care of the Academic Faculty?" Research in Higher Education First Online: 05 April 2017:1-23.

Gupta, Suman, Jernej Habjan, and Hrvoje Tutek. 2016. "Academic Labour, Unemployment and Global Higher Education." In. London: Palgrave Macmillan UK.

Hassan, Robert. 2017. "The worldly space: the digital university in network time." British Journal of Sociology of Education 38 (1):72-82. doi: 10.1080/01425692.2016.1234364.

Henderson, Emily. 2019. "The (un)invited guest? Feminist pedagogy and guest lecturing " Teaching in Higher Education 24 (1):115-20. doi: 10.1080/13562517.2018.1527766.

James, Nalita. 2016. "Using email interviews in qualitative educational research: creating space to think and time to talk." International Journal of Qualitative Studies in Education 29 (2):15063. doi: 10.1080/09518398.2015.1017848.

Karpouza, Eleni, and Anastassios Emvalotis. 2019. "Exploring the teacher-student relationship in graduate education: a constructivist grounded theory." Teaching in Higher Education 24 (2):121-40. doi: 10.1080/13562517.2018.1468319.

Klopper, Christopher J., and Bianca M. Power. 2014. "The Casual Approach to Teacher Education: What Effect Does Casualisation Have for Australian University Teaching?" Australian Journal of Teacher Education 39 (4).

Lama, Tek, and Jean-Etienne Joullié. 2015. "Casualization of Academics in the Australian Higher Education: Is Teaching Quality at Risk?" Research in Higher Education Journal 28.

Leccardi, Carmen. 2005. "Facing uncertainty: Temporality and biographies in the new century." Young: Nordic Journal of Youth Research 13:123-46. doi: 10.1177/1103308805051317.

Lennon, Sherilyn, Tasha Riley, and Sue Monk. 2018. "The uncomfortable teacher-student encounter and what comes to matter." Teaching in Higher Education 23 (5):619-30. doi: 10.1080/13562517.2018.1458711. 
Lingard, Bob, and Greg Thompson. 2017. "Doing time in the sociology of education." British Journal of Sociology of Education 38 (1):1-12. doi: 10.1080/01425692.2016.1260854.

Lopes, Ana, and Indra Angeli Dewan. 2014. "Precarious Pedagogies? The Impact of Casual and ZeroHour Contracts in Higher Education." Journal of Feminist Scholarship 7/8 (Fall 2014/Spring 2015):28-42.

Lorey, Isabel. 2015. State of Insecurity: Government of the Precarious. English edition ed. London: Verso.

Loveday, Vik. 2017. "'Luck, chance, and happenstance? Perceptions of success and failure amongst fixed-term academic staff in UK higher education'." The British Journal of Sociology fortcoming:n/a-n/a. doi: 10.1111/1468-4446.12307.

Lukacs, Georg. 1971. History and Class Consciousness. Cambridge, MA, USA: MIT Press.

Lynch, Kathleen. 2010. "Carelessness: A hidden doxa of higher education." Arts and Humanities in Higher Education 9 (1):54-67.

Motta, Sara C., and Anna Bennett. 2018. "Pedagogies of care, care-full epistemological practice and 'other' caring subjectivities in enabling education." Teaching in Higher Education 23 (5):63146. doi: 10.1080/13562517.2018.1465911.

Noonan, Jeff. 2015. "Thought-time, money-time and the conditions of free academic labour." Time \& Society $0(0): 1-21$.

O'Keefe, Theresa, and Aline Courtois. 2019. "'Not one of the family': Gender and precarious work in the neoliberal university." Gender, Work \& Organization 26 (4):463-79. doi: 10.1111/gwao.12346.

Peters, Michael A. 2015. "The University in the Epoch of Digital Reason: Fast knowledge in the circuits of cybernetic capitalism." Analysis and Metaphysics 14:38-58.

Read, Barbara, and Carole Leathwood. 2018. "Tomorrow's a mystery: constructions of the future and 'un/becoming' amongst 'early' and 'late' career academics." International Studies in Sociology of Education:1-19. doi: 10.1080/09620214.2018.1453307.

Rosa, Hartmut. 2015. Social Acceleration: A New Theory of Modernity. New York: Columbia University Press.

Sabelis, Ida. 2008. "Time Regimes - Power and synchonization in organizations." KronoScope 8 (2):12530.

Shahjahan, Riyad A. 2015. "Being 'Lazy' and Slowing Down: Toward decolonizing time, our body, and pedagogy." Educational Philosophy and Theory 47 (5):488-501. doi: 10.1080/00131857.2014.880645.

Street, Steve, Maria Maisto, Esther Merves, and Gary FRhodes. 2012. "Who is Professor 'Staff' and How Can This Person Teach So Many Classes?" In. Akron, OH: Centre for the Future of Higher Education Policy Report 2.

UCU. 2016. "Precarious work in higher education: A snapshot of insecure contracts and institutional attitudes." In, London.

Walker, Judith. 2009. "Time as the Fourth Dimension in the Globalization of Higher Education." The Journal of Higher Education 80 (5):483-509.

Ylijoki, Oili-Helena. 2010. "Future orientations in episodic labour: Short-term academics as a case in point." Time \& Society 19 (3):365-86. doi: 10.1177/0961463×10356220. 
- - . 2015. "Conquered by Project Time? Conflicting temporalities in university research." In Universities in the Flux of Time: An exploration of time and temporality in university life, edited by Paul Gibbs, Oili-Helena Ylijoki, Carolina Guzman-Valenzuela and Ronald Barnett, 94-107. London: Routledge.

Zheng, Robin. 2018. "Precarity is a Feminist Issue: Gender and Contingent Labor in the Academy." Hypatia 33 (2):235-55. 